\title{
The chlorophyll a fluorescence as an indicator of the temperature stress in the leaves of Prunus persica
}

\author{
Emanuela Garbin Martinazzoํㅜ, Aline Ramm¹, Marcos Antonio Bacarin* \\ Universidade Federal de Pelotas, Instituto de Biologia, Departamento de Botânica, Laboratório de Metabolismo \\ Vegetal, Pelotas, RS, Brazil.
}

${ }^{\star}$ Corresponding author: bacarin@ufpel.edu.br

Received: 11 July 2012; Accepted: 13 November 2012

\begin{abstract}
Plants growing in temperate regions are often exposed to stress conditions caused by high temperatures. Photosynthesis is one of the metabolic processes most sensitive to high temperature stress, and it is often inhibited before other cellular functions. Using peach leaf disks, we studied the transient chlorophyll a fluorescence along with the gas exchanges at temperatures of 25 (control) $30,35,40$ and $45^{\circ} \mathrm{C}$ in the dark for a period of 30 minutes. Temperatures above $35^{\circ} \mathrm{C}$ caused significant changes in the transient fluorescence of chlorophyll $a$, including an increase in the initial fluorescence $\left(F_{0}\right)$, a decrease in maximum fluorescence values $\left(F_{M}\right)$ and the appearance of $K$ and $L$ bands. The values of the net assimilation rate decreased as the temperature increased and reached negative values at $45^{\circ} \mathrm{C}$.
\end{abstract}

Keywords: high temperature, photosynthesis, Prunus persica.

\section{INTRODUCTION}

The chlorophyll (Chl) a fluorescence represents a very small fraction of the energy that is dissipated from the photosynthetic mechanism, but it is widely used to provide information about the structure and function of the electron transport chain (Strasser et al., 2004). Measuring $\mathrm{Chl}$ a fluorescence provides basic information about the photosynthetic mechanism of plants; it has been used to detect changes in photosystem II (PSII) that occur under stress conditions, and it can easily be performed using intact leaves or isolated chloroplasts (Yamane et al., 2000).

Photosynthesis is highly sensitive to stress caused by extreme temperatures, and it is often inhibited before other cellular functions are harmed (Chen and Cheng, 2009). Plants exposed to high temperatures exhibit two opposite effects in the electron transport chain of photosynthesis (Tóth et al., 2007). Photosystem I (PSI) is stimulated by heat (as measured by the rate of $\mathrm{P} 700^{+}$ reduction) due to greater reduction of the plastoquinone (PQ) pool by ferredoxin ( $\mathrm{Fd}$ ) at high temperatures (Tóth et al., 2007). In contrast, photosystem II (PSII), particularly the oxygen-evolving complex (OEC), is deactivated even at slightly elevated temperatures (Yamane et al., 1998), demonstrating that this process is especially sensitive to temperature stress (Pushpalatha et al., 2008).

When photosynthetic samples adapted to the dark are illuminated, changes occur in the intensity of the Chl a fluorescence. This is known as the Kautsky effect (Strauss et al., 2006). The transient curve displays a rapid increase that ends in less than one second, with a subsequent slow decline toward a steady state. It is postulated that the phase of rapid increase represents the primary photosynthesis reactions (Strauss et al., 2006). When this transient phase is monitored with high-resolution fluorometers, it provides precise information on the energetic state of the photosynthetic mechanisms (Strasser et al., 1995). It is known that the kinetics of fluorescence transients are polyphasic when plotted on a logarithmic time scale. 
Such plots clearly indicate the intermediate $\mathrm{J}$ and I steps between the initial step 0 and the maximum final level $P$ (Strasser and Govindjee, 1992).

The JIP-test, proposed by Strasser and Strasser (1995), is used to translate the original measurements of fluorescence transient into various phenomenological and biophysical expressions that quantify the function of PSII (Tóth et al., 2007). The JIP-test can be applied to in vivo studies of the photosynthetic process because the typical fluorescence transient is sensitive to the stress caused by changes in many environmental conditions, making it a very sensitive indicator of the biophysical processes of the electron transport chain (ETC) (Tóth et al., 2007). The inhibition of the ETC is followed by the functional separation of the light-harvesting complexes of PSII (LHCII), blocking off the flux of electrons from $Q_{A}$ to $Q_{B}$ (Petkova et al., 2007).

Thermal stress causes significant changes in the fluorescence transient of chlorophyll $a$, including an increase in the initial fluorescence $\left(F_{0}\right)$ and a decrease in the maximum fluorescence values $\left(\mathrm{F}_{\mathrm{M}}\right)$. An additional peak at approximately $0.3 \mathrm{~ms}$ can also be observed, which is called band K (Oukarroum et al., 2012).

The objective of this study was to evaluate the effects of different temperatures on photosynthetic activity, as measured by the $\mathrm{Chl}$ a fluorescence and gas exchange rates in peach leaf disc.

\section{MATERIAL AND METHODS}

Plant material and treatments: Adult peach plants (Prunus persica) of the PE-36 cultivar were grown in an experimental field of the Federal University of Pelotas, Capão do Leão Campus, RS, Brazil (31 $48^{\prime} 11$ 'S and $\left.52^{\circ} 24^{\prime} 58^{\prime \prime} \mathrm{W}\right)$. Mature completely leaves were collected, and leaf discs with an area of $1,000 \mathrm{~mm}^{2}$ were extracted. Twelve leaves were used per treatment, and they were conditioned using clips. The leaf disc and clip combination was wrapped in absorbent paper that had been moistened with distilled water, and it was protected by an envelope made of aluminium foil. These packets were exposed to different temperatures $\left(25,30,35,40\right.$ and $\left.45^{\circ} \mathrm{C}\right)$ for a period of 30 min by immersion in a water bath. The $25^{\circ} \mathrm{C}$ treatment was used as the control.

After immersion, the samples were carefully removed from the water bath so that the Chl a fluorescence transient and gas exchange be measured.
Analysis of the induction of $\mathrm{Chl}$ a fluorescence: Measurements of the $\mathrm{Chl}$ a fluorescence were taken immediately after each temperature treatment using a Handy-PEA portable fluorometer (Hansatech Instruments Ltd., King's Lynn Norfolk, UK). The fluorescence transient was induced by red light, with a peak at $650 \mathrm{~nm}$ and approximately $3,000 \mu \mathrm{mol} \mathrm{m} \mathrm{m}^{-2} \mathrm{~s}^{-1}$, and was provided by a set of three light-emitting diodes with a recording time of $1 \mathrm{~s}$. Fluorescence intensity was measured between 50 $\mu \mathrm{s}$ and $1 \mathrm{~s}$.

JIP-test, normalisation and subtractions of the fluorescence transient curves: The fluorescence intensities determined at 50, 100 and $300 \mu \mathrm{s}\left(\mathrm{F}_{50 \mu \mathrm{s}}, \mathrm{F}_{100 \mu \mathrm{s}}\right.$ and $\mathrm{F}_{300 \mu \mathrm{s}}$, respectively), 2 and $30 \mathrm{~ms}\left(F_{2 \mathrm{~ms}}=F_{\mathrm{J}}\right.$ and $\left.F_{30 \mathrm{~ms}}=F_{1}\right)$ and at $F_{M}$ (maximum fluorescence) were used to calculate the JIP-test parameters (Strasser and Strasser 1995). The intensity measured at $50 \mu \mathrm{s}$ was considered to be the initial fluorescence $\left(\mathrm{F}_{0}\right)$. The $\mathrm{Chl}$ a fluorescence transient was analysed using the JIP-test using 'Biolyzer' software (Laboratory of Bioenergetics, University of Geneva, Switzerland).

For comparison of the events represented by the OK, $\mathrm{OI}$ and IP phases, the transient curves were normalised as the relative variable fluorescence as: $W_{0 K}=\left(F_{t}-F_{0}\right) /$ $\left(F_{K}-F_{0}\right), W_{0 J}=\left(F_{t}-F_{0}\right) /\left(F_{j}-F_{0}\right), W_{01}=\left(F_{t}-F_{0}\right) /\left(F_{1}-F_{0}\right)$ and $W_{I P}=\left(F_{t}-F_{1}\right) /\left(F_{M}-F_{1}\right)($ Tsimilli-Michael and Strasser, 2008). For analysis of the different kinetics, the divergences (differences) between the relative variable fluorescence curves of the stress treatments and control were calculated $\left(\Delta \mathrm{W}=\mathrm{W}_{\text {treatment }}-\mathrm{W}_{\text {control }}\right)$; this procedure reveals bands that are normally hidden between steps 0 and $P$ on the relative variable fluorescence.

Leaf gas exchange: After determining the fluorescence transient, the rates of $\mathrm{CO}_{2}$ exchange were measured using a portable $\mathrm{CO}_{2}$ analyser (model LI-6400XT LI-COR, Inc., Lincoln, NE, USA). The measurements were performed in a chamber with a $\mathrm{CO}_{2}$ concentration of $380 \mu \mathrm{mol} \mathrm{mol}^{-1}$ and a photon flux density of $1,200 \mu \mathrm{mol} \mathrm{m} \mathrm{m}^{-2} \mathrm{~s}^{-1}$.

Statistical analysis: The results obtained for the parameters of the JIP test were subjected to an analysis of variance (ANOVA); when the F-test was significant, a comparison of means was performed via the Tukey's test.

\section{RESULTS}

The leaf discs incubated at 25,30 and $35^{\circ} \mathrm{C}$ exhibited typical fluorescence transient curves. However, those that 
were incubated at 40 and $45^{\circ} \mathrm{C}$ displayed imbalances with the characteristic 0JIP steps (Figure 1).

In Table 1 , it can be observed that $\mathrm{F}_{0}$ and $\mathrm{F}_{\text {300us }}$ display significant increases at 40 and $45^{\circ} \mathrm{C}$, with their highest values measured in the leaf discs exposed to $45^{\circ} \mathrm{C}$.

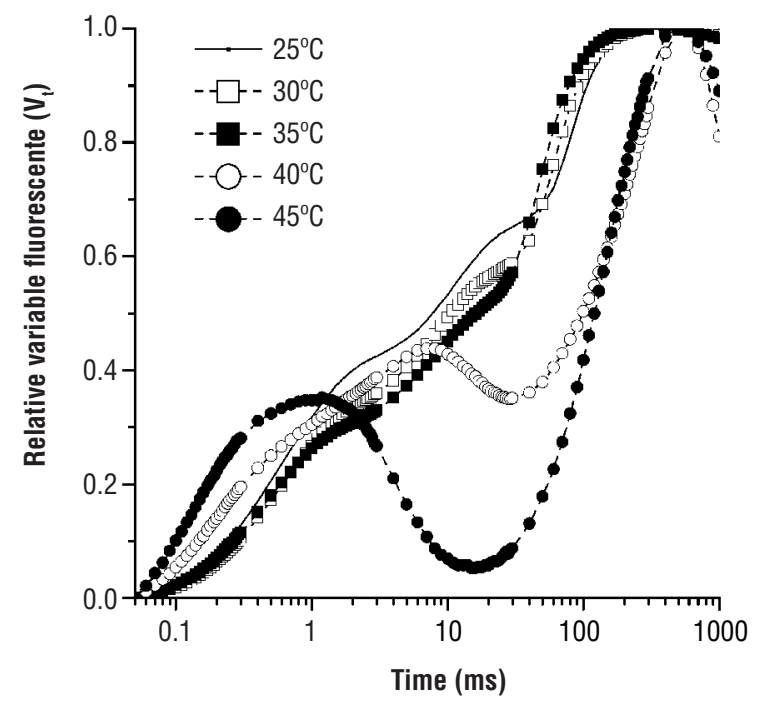

Figure 1. Presentation of the $\mathrm{Chl}$ a fluorescence data $\mathrm{F}_{\mathrm{f}}$ as kinetics of the relative variable fluorescence $\left[V_{t}=\left(F_{t}-F_{0}\right)\right.$ / $\left(F_{M}-F_{0}\right)$, arbitrary unit] exhibited by leaf discs of peach subjected to different temperature.
For the fluorescence intensity at step $\mathrm{J}\left(\mathrm{F}_{\mathrm{J}}\right)$, the greatest values were identified at a temperature of $25^{\circ} \mathrm{C}$ and the lowest values at 35 and $40^{\circ} \mathrm{C}$. The fluorescence intensity at step $I\left(F_{1}\right)$ and the maximum fluorescence $\left(F_{M}\right)$ displayed significant decreases beginning at $35^{\circ} \mathrm{C}$, with the lowest values obtained at 40 and $45^{\circ} \mathrm{C}$. (Table 1)

The flux of absorption and trapping per reaction center (RC) of PSII, defined as $A B S / R C$ and $T R_{0} / R C$, respectively, were significantly greater in the leaf discs incubated at 40 and $45^{\circ} \mathrm{C}$ (Table 1). Electron transport flux per RC of PSIl defined as $\mathrm{ET}_{0} / \mathrm{RC}$ began increasing at a temperature of $35^{\circ} \mathrm{C}$; this value was similar at that at $40^{\circ} \mathrm{C}$, but it was lower than the value obtained at $45^{\circ} \mathrm{C}$. It was not possible to estimate the flux Reduction of End-electron acceptors ( $\mathrm{RE}_{0} / \mathrm{RC}$ ) for temperatures of 40 and $45^{\circ} \mathrm{C}$ due to a change in the shape of the kinetic fluorescence emission curve (Figure 1). Thus, values were calculated only for temperatures between 25 and $35^{\circ} \mathrm{C}$, with significant increases in the values accompanying the increase in temperature (Table 1).

With regard to the parameters that describe the yields and efficiency of the electron transport chain (ETC), the following can be observed in Table 1: (a) maximum quantum yield of primary photochemistry (at $t=0$ ) $\left(\varphi_{\mathrm{P}_{0}}=F_{\mathrm{v}} / F_{\mathrm{M}}=T R_{0} / A B S\right)$ and the quantum yield of electron transport between PSII and PSI (at $t=0)\left(\varphi_{E_{0}}=E_{0} / A B S\right)$

Table 1. Intensity chlorophyll a fluorescence and some parameters of the JIP-test from the fluorescence transient exhibited by leaf discs of peach subjected to different temperature.

\begin{tabular}{|c|c|c|c|c|c|c|}
\hline \multirow{2}{*}{ Temperature } & \multicolumn{6}{|c|}{ Intensity chlorophyll a fluorescence (relative unit) } \\
\hline & $\mathrm{F}_{0}$ & $\mathrm{~F}_{\mathrm{K}}(300 \mu \mathrm{s})$ & $F_{J}(2 \mathrm{~ms})$ & $\mathrm{F}_{1}(30 \mathrm{~ms})$ & $\mathrm{F}_{\mathrm{M}}$ & $\mathrm{F}_{\mathrm{v}} / \mathrm{F}_{0}$ \\
\hline $25^{\circ} \mathrm{C}$ & $366 \pm 5 c$ & $562 \pm 13 c$ & $980 \pm 18 a$ & $1.366 \pm 20 \mathrm{a}$ & $1.900 \pm 38 a$ & $4.21 \pm 0.46 \mathrm{a}$ \\
\hline $30^{\circ} \mathrm{C}$ & $355 \pm 7 c$ & $522 \pm 12 \mathrm{~cd}$ & $888 \pm 21 b$ & $1.292 \pm 47 a$ & $1.950 \pm 45 a$ & $4.48 \pm 0.18 \mathrm{a}$ \\
\hline $35^{\circ} \mathrm{C}$ & $332 \pm 8 c$ & $492 \pm 15 d$ & $761 \pm 29 c d$ & $1.131 \pm 29 b$ & $1.730 \pm 44 b$ & $4.21 \pm 0.26 \mathrm{a}$ \\
\hline $40^{\circ} \mathrm{C}$ & $456 \pm 10 b$ & $621 \pm 16 b$ & $750 \pm 16 d$ & $746 \pm 14 c$ & $1.266 \pm 44 \mathrm{c}$ & $1.73 \pm 0.38 b$ \\
\hline $45^{\circ} \mathrm{C}$ & $729 \pm 18 \mathrm{a}$ & $852 \pm 18 \mathrm{a}$ & $872 \pm 27 \mathrm{bc}$ & $767 \pm 21 \mathrm{c}$ & $1.167 \pm 44 \mathrm{c}$ & $0.61 \pm 0.16 c$ \\
\hline \multirow{2}{*}{ Temperature } & \multicolumn{6}{|c|}{ Flux per reaction centers (relative unit) } \\
\hline & $\mathrm{ABS} / \mathrm{RC}$ & $\mathrm{TR}_{0} / \mathrm{RC}$ & $\mathrm{ET}_{0} / \mathrm{RC}$ & $\mathrm{RE}_{0} / \mathrm{RC}$ & & \\
\hline $25^{\circ} \mathrm{C}$ & $1.58 \pm 0.04 \mathrm{c}$ & $1.12 \pm 0.02 \mathrm{c}$ & $0.75 \pm 0.01 c$ & $0.44 \pm 0.01 \mathrm{c}$ & & \\
\hline $30^{\circ} \mathrm{C}$ & $1.52 \pm 0.02 \mathrm{c}$ & $1.25 \pm 0.01 \mathrm{c}$ & $0.83 \pm 0.01 \mathrm{c}$ & $0.51 \pm 0.01 b$ & & \\
\hline $35^{\circ} \mathrm{C}$ & $1.84 \pm 0.04 \mathrm{c}$ & $1.49 \pm 0.02 \mathrm{c}$ & $1.03 \pm 0.02 b$ & $0.63 \pm 0.01 a$ & & \\
\hline $40^{\circ} \mathrm{C}$ & $3.52 \pm 0.16 \mathrm{~b}$ & $2.19 \pm 0.05 b$ & $1.38 \pm 0.02 b$ & - & & \\
\hline $45^{\circ} \mathrm{C}$ & $10.17 \pm 1.06 a$ & $3.71 \pm 0.25 a$ & $2.58 \pm 0.31 \mathrm{a}$ & - & & \\
\hline \multirow{2}{*}{ Temperature } & & Yield & \multicolumn{4}{|c|}{ Efficiency/probability } \\
\hline & $\varphi_{\mathrm{P}_{0}}$ & $\varphi_{\mathrm{E}_{0}}$ & $\varphi_{\mathrm{R} 0}$ & $\psi_{\mathrm{E} 0}$ & $\delta_{\mathrm{Ro}}$ & \\
\hline $25^{\circ} \mathrm{C}$ & $0.807 \pm 0.005 a$ & $0.482 \pm 0.018 \mathrm{~b}$ & $0.280 \pm 0.007 \mathrm{~b}$ & $0.59 \pm 0.01^{\mathrm{ns}}$ & $0.58 \pm 0.01^{\mathrm{ns}}$ & \\
\hline $30^{\circ} \mathrm{C}$ & $0.817 \pm 0.001 \mathrm{a}$ & $0.544 \pm 0.006 a$ & $0.339 \pm 0.009 a$ & $0.66 \pm 0.01$ & $0.62 \pm 0.01$ & \\
\hline $35^{\circ} \mathrm{C}$ & $0.808 \pm 0.003 a$ & $0.560 \pm 0.013 a$ & $0.346 \pm 0.007 a$ & $0.69 \pm 0.01$ & $0.62 \pm 0.01$ & \\
\hline $40^{\circ} \mathrm{C}$ & $0.627 \pm 0.016 b$ & $0.401 \pm 0.022 \mathrm{c}$ & - & $0.63 \pm 0.02$ & - & \\
\hline $45^{\circ} \mathrm{C}$ & $0.375 \pm 0.022 \mathrm{c}$ & $0.254 \pm 0.025 d$ & - & $0.67 \pm 0.04$ & - & \\
\hline
\end{tabular}

Means \pm standard error, $n=9$ to 15 , Tukey's test $p<0.05$. 
both displayed significantly lower values in the leaves exposed to 40 and $45^{\circ} \mathrm{C}$; (b) the quantum yield of electron transport from $Q_{A}{ }^{-}$to the PSI end electron acceptors $\left(\varphi_{\mathrm{Ro}}=\mathrm{RE}_{0} / \mathrm{ABS}\right)$, calculated only for temperatures between 25 and $35^{\circ} \mathrm{C}$, was significantly lower for the leaves exposed to $25^{\circ} \mathrm{C}$; and (c) neither the efficiency with which a trapped exciton can move an electron into the electron transport chain from $Q_{A}$ to the intersystem electron acceptors $\left(\mathrm{ET}_{0} / \mathrm{TR}_{0}=\psi_{\mathrm{E}_{0}}=1-\mathrm{V}_{\mathrm{J}}\right)$ nor the efficiency with which an electron can move from the reduced intersystem electron acceptors to the PSI end electron acceptors $\left(\mathrm{RE}_{0} / \mathrm{ET}_{0}=\delta_{\mathrm{RO}_{0}}\right)$, calculated only for temperatures between 25 and $35^{\circ} \mathrm{C}$, were affected by the temperature differences.

The performance index $\left(\mathrm{PI}_{\mathrm{ABS}}\right)$ is a parameter thought to be sensitive to various types of stress; it is widely used to compare primary photochemical reactions (Strasser et al., 2000), given that it incorporates the energy cascade processes from the first absorption events until the reduction of plastoquinone. The highest values for $\mathrm{PI}_{A B S}$ were obtained when the leaves were exposed to 30 and $35^{\circ} \mathrm{C}$, with lower values observed at $40^{\circ} \mathrm{C}$ and minimum values obtained at $45^{\circ} \mathrm{C}$ (Figure 2).

The normalisation of the fluorescence curves between steps $0(50 \mu \mathrm{s})$ and $\mathrm{K}(300 \mu \mathrm{s})$ (Figure $3 \mathrm{~A}-\mathrm{B})$ and between $0(50 \mu \mathrm{s})$ and $\mathrm{J}(2 \mu \mathrm{s})$ (Figure $3 \mathrm{C}-\mathrm{D})$ in terms of relative variable fluorescence $\left(W_{0 K}\right.$ and $\left.W_{O J}\right)$, together with the analysis of the kinetic differences $\left[\Delta \mathrm{W}_{0 \mathrm{~K}}\right.$ and $\left.\Delta \mathrm{W}_{\mathrm{OJ}}\right]$, permitted the identification of positive $L$ and $K$ bands, at approximately 150 and $300 \mu \mathrm{s}$, respectively, in the leaf discs exposed to 40 and $45^{\circ} \mathrm{C}$; the largest amplitudes for both bands were observed at $45^{\circ} \mathrm{C}$.

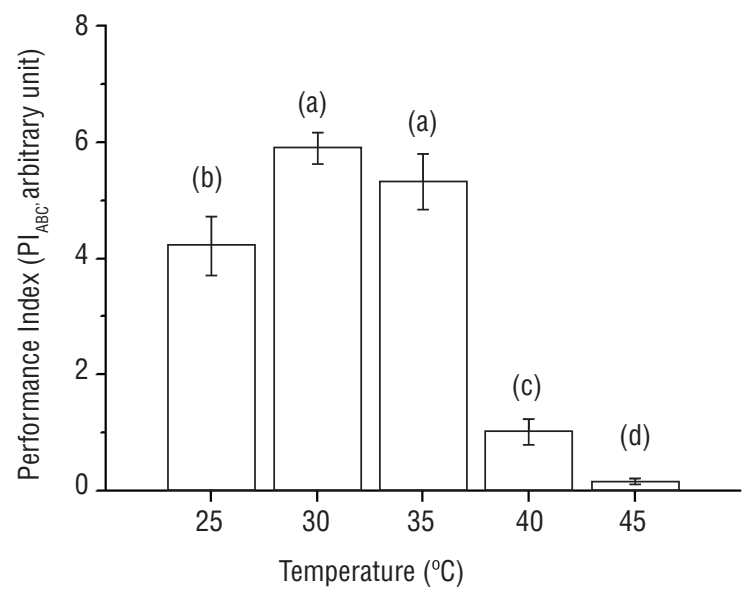

Figure 2. Performance Index $\left(\mathrm{PI}_{\mathrm{ABS}}\right.$, arbitrary unit) of the leaf discs of peach subjected to different temperature. Bar indicates standard error $(n=10)$. The different letters indicate significant difference at $p<0.05$ (Tukey's test).
With regard to the normalisation of the fluorescence curves between steps $0(50 \mu \mathrm{s})$ and I ( $30 \mathrm{~ms})$, the relative variable fluorescence greater than 1 (Figure $4 \mathrm{~A}$ ) and less than 1 was calculated only for temperatures between 25 and $35^{\circ} \mathrm{C}$. A larger pool of electron acceptors can be found at lower temperatures than at higher temperatures (Figure 4).

With regard to the gaseous exchange parameters, it can be observed that the net rate of assimilation significantly decreased beginning at a temperature of $35^{\circ} \mathrm{C}$; for $45^{\circ} \mathrm{C}$, this value can even be converted into negative (Figure $5 \mathrm{~A}$ ). In contrast, the transpiration rates of leaf discs exposed to $45^{\circ} \mathrm{C}$ were twice as high as those observed between temperatures of 25 and $35^{\circ} \mathrm{C}$, with the lowest values observed at $40^{\circ} \mathrm{C}$ (Figure 5B).

The stomatal conductance was statistically greater for the leaves incubated at $45^{\circ} \mathrm{C}$, and it remained at approximately $0.24 \mathrm{~mol} \mathrm{H}_{2} \mathrm{O} \mathrm{m}^{-2} \mathrm{~s}^{-1}$ when temperatures between 25 and $35^{\circ} \mathrm{C}$ were used; its lowest values were noted at $40^{\circ} \mathrm{C}$ (Figure $5 \mathrm{C}$ ). With regard to the intercellular $\mathrm{CO}_{2}$ concentration $(\mathrm{Ci})$, the leaf discs incubated at $45^{\circ} \mathrm{C}$ achieved the highest $\mathrm{Ci}$ values in contrast to the other temperatures that were studied (Figure 5D). Similar behaviour was observed for the $\mathrm{Ci} / \mathrm{Ca}$ ratio (Figure $5 \mathrm{E}$ ).

\section{DISCUSSION}

The flux of absorption and trapping per reaction center (RC) of PSII, defined as ABS/RC, the maximal energy trapping flux per $\mathrm{RC}$ written as $\mathrm{TR}_{0} / \mathrm{RC}$ and the maximal electron transport between PSII and PSI per reaction center of PSII (written as ET/RC) and the Reduction of the End-electron acceptors of PSI (written as $\mathrm{RE}_{0} / \mathrm{RC}$ ) exhibited the highest values in high temperature. This can be thought of as partly due to the small number of active reaction centres in PS II (Lawlor and Tezara, 2009). This characteristic applies to all of the measured parameters when the leaves are exposed to temperatures of 40 and, in particular, $45^{\circ} \mathrm{C}$.

The rapid increase in the fluorescence intensity, a consequence of the reduction of the electron acceptors beyond PSII, was affected by the different temperature treatments. The highest intensity of $F_{0}$ was identified for the peach leaf discs incubated at $45^{\circ} \mathrm{C}$. This parameter represents the number of open reaction centres, or, rather, the first electron acceptor of PSII, $Q_{A}$ in its oxidised state. However, the increase in $F_{0}=A B S\left[k_{F} /\left(k_{P}+k_{N}\right)\right]$, derived in terms of the de-excitation rate constants, 

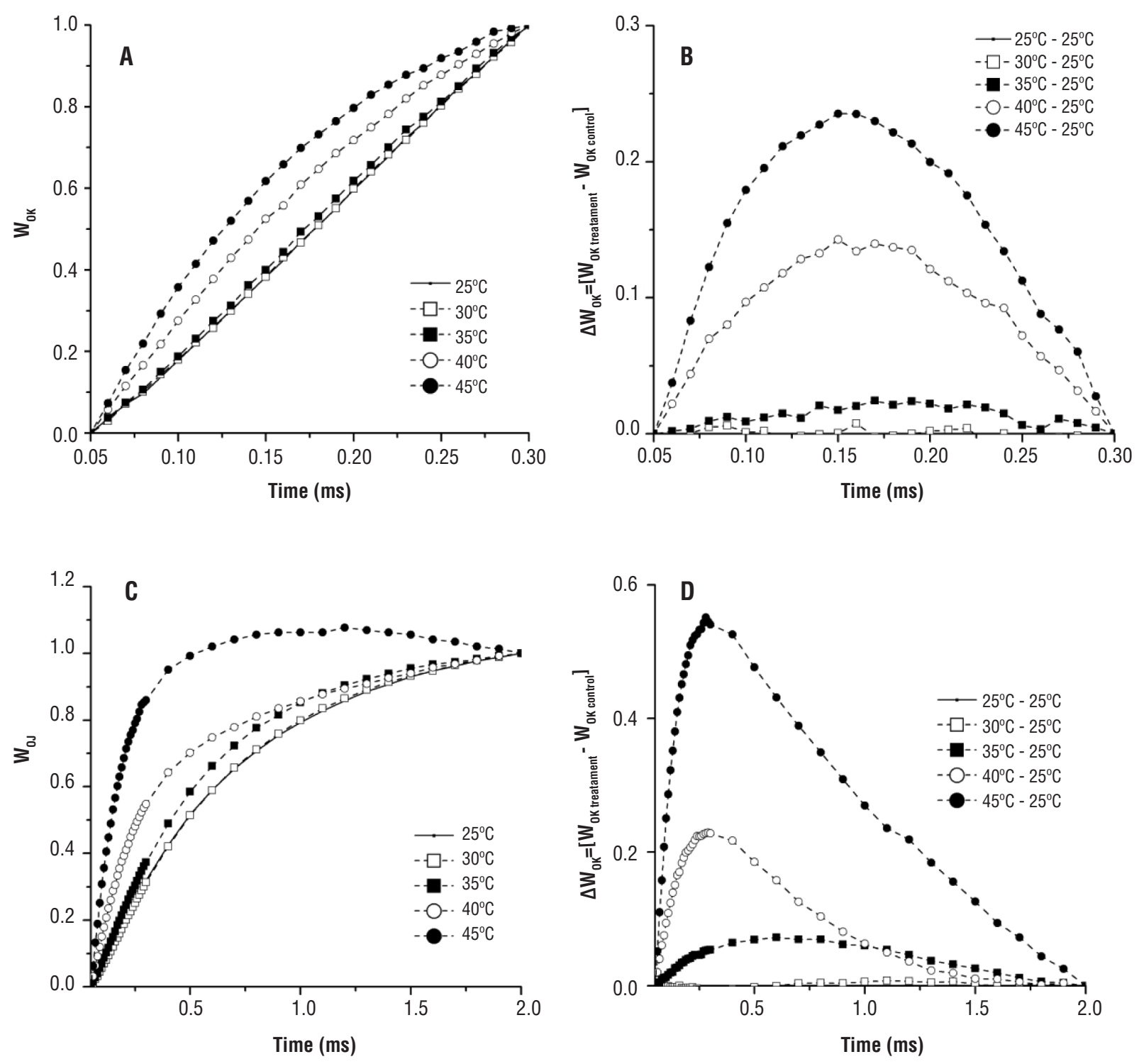

Figure 3. Presentation of the $\mathrm{Chl}$ a fluorescence data $F_{t}$ as the difference kinetics $(\Delta W)$ of the leaf discs of peach subjected to different temperature. The $\Delta \mathrm{W}$ kinetics refer to the differences of the $\mathrm{W}$ of all cases from that of the stress-temperature from control $\left(25^{\circ} \mathrm{C}\right)$, i.e. $30-25^{\circ} \mathrm{C}, 35-25^{\circ} \mathrm{C}, 40-25^{\circ} \mathrm{C}$ and $45-25^{\circ} \mathrm{C}$. (A) relative variable fluorescence between steps 0 and $\mathrm{K}\left[\mathrm{W}_{\mathrm{oK}}=\left(\mathrm{F}_{\mathrm{t}}-\mathrm{F}_{0}\right) /\left(\mathrm{F}_{\mathrm{K}}-\mathrm{F}_{0}\right)\right] ;(\mathrm{B})$ difference kinetics of the $W_{0 K}\left[\Delta W_{0 K}=W_{O K(\text { treatment) }}-W_{\text {OK(control) }}\right] ;(C)$ relative variable fluorescence between steps 0 and $J\left[W_{0 J}=\left(F_{t}-F_{0}\right) /\left(F_{J}-F_{0}\right)\right] ;(D)$ difference kinetics of the $\mathrm{W}_{0 \mathrm{~J}}\left[\Delta \mathrm{W}_{0 \mathrm{~J}}=\left(\mathrm{W}_{\mathrm{OJ}(\text { (treatment) }}-\mathrm{W}_{\mathrm{OJ}(\text { control) }}\right]\right.$.

in which $\mathrm{k}_{\mathrm{F}}=$ rate constant for fluorescence emission, $\mathrm{k}_{\mathrm{p}}=$ photochemical de-excitation rate constant and $k_{N}=$ non-photochemical de-excitation rate constant, under stress may be due to changes in the light absorption flux because of scatter changes as a result of turgor changes and/or structural changes due to changes in $k_{p}$ and/or $k_{N}$ and various other processes such as: (a) the dissociation of the light-harvesting complexes of PSII and the accumulation of inactive, non $Q_{A}$ reducing $R C s ;$ (b) the re-reduction of $Q_{A}$ to $Q_{A}{ }^{-}$in the dark, via reduced plastoquinone pool; (c) the transfer of electrons from $Q_{B}$ to $Q_{A}$; and (d) the monomerisation of the light-harvesting complexes of PSII (LHCII) induced by heat (Chen et al., 2008).

The increase in $\mathrm{F}_{0}$ can be interpreted as indicating irreversible damage to PSII caused by uncontrolled dissipation of heat that produces an excess of excitation 

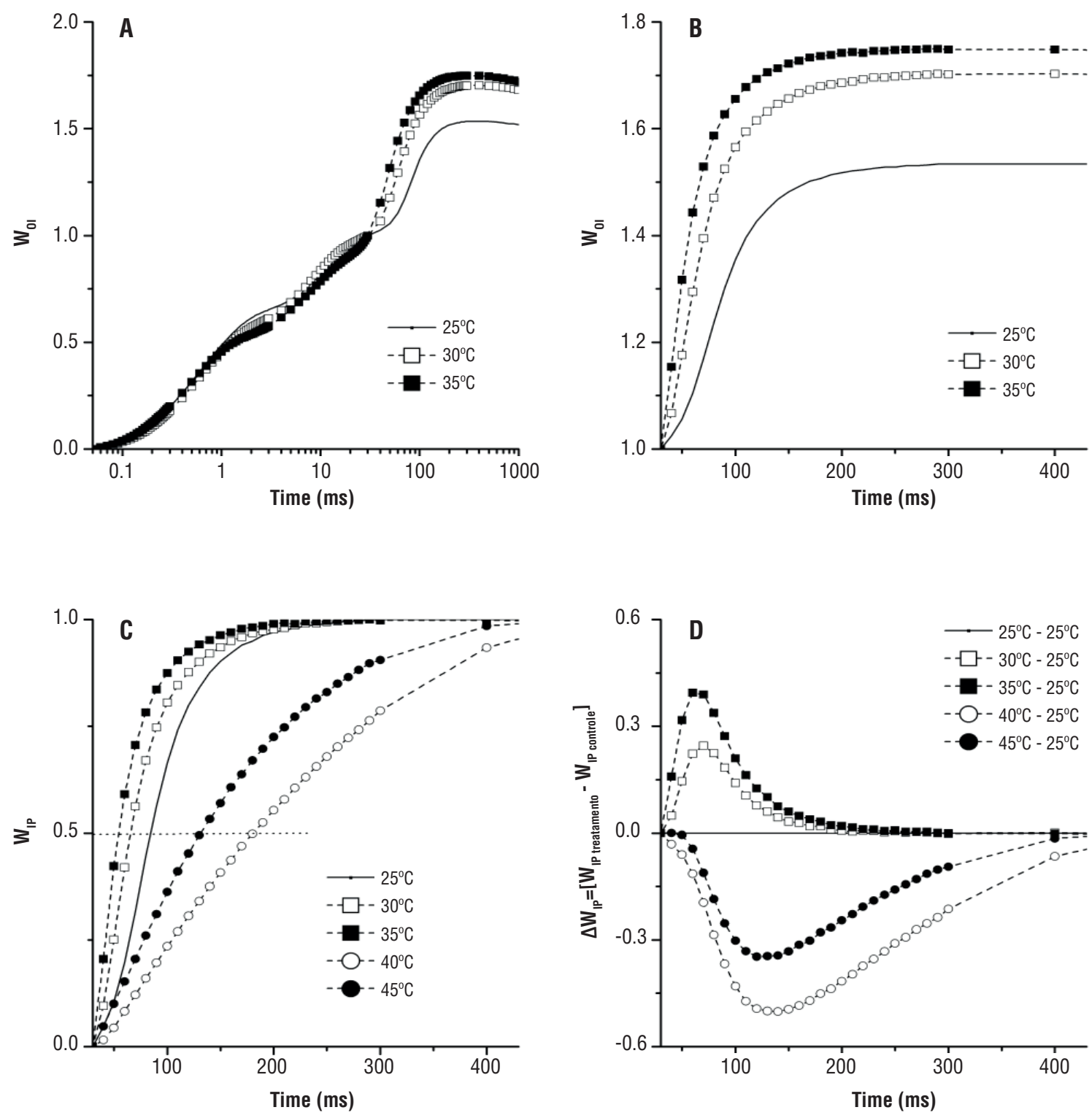

Figure 4. Presentation of the $\mathrm{Chl}$ a fluorescence data $\mathrm{F}_{t}$ as the difference kinetics $(\Delta \mathrm{W})$ of the leaf discs of peach subjected to different temperature. The $\Delta \mathrm{W}$ kinetics refer to the differences of the $\mathrm{W}$ of all cases from that of the stress-temperature from control $\left(25^{\circ} \mathrm{C}\right)$, i.e. $30-25^{\circ} \mathrm{C}, 35-25^{\circ} \mathrm{C}, 40-25^{\circ} \mathrm{C}$ and $45-25^{\circ} \mathrm{C}$. (A) relative variable fluorescence between steps 0 and I $\left[W_{01}=\left(F_{t}-F_{0}\right) /\left(F_{1}-F_{0}\right)\right] ;(B) W_{01}$ in time between 30 and $430 \mathrm{~ms} ;(C)$ relative variable fluorescence between steps I and $P\left[W_{I P}=\left(F_{t}-F_{I}\right) /\left(F_{P}-F_{I}\right)\right]$; (D) (B) difference kinetics of the $\mathrm{W}_{\mathrm{IP}}\left[\Delta \mathrm{W}_{\mathrm{IP}}=\mathrm{W}_{\mathrm{IP}(\text { treatment) }}-\mathrm{W}_{\mathrm{IP}(\text { control) }}\right]$.

energy (Bussotti et al., 2011). The increase in $F_{0}$ may have contributed to values close to the control values for the fluorescence intensities measured at $2 \mathrm{~ms}\left(\mathrm{~F}_{2 \mathrm{~ms}}\right.$ or the $\mathrm{J}$ step). In this case, for leaves exposed to mild temperatures, the accumulation of $Q_{A}{ }^{-}$occurs due to the energy cascade initiated after the illumination of a sample that was adapted to the dark. However, the fact that the fluorescence intensity at $F_{2 m s}$ approaches values very close to those found at temperatures of 25 and $30^{\circ} \mathrm{C}$, even when the leaf discs are exposed to $45^{\circ} \mathrm{C}$. This may be explained by the nearly constant concentration of reduced $Q_{A}$ which is located in the very close surroundings of the reduced plastoquinone pool, even in the dark.

The fluorescence intensity at step I $\left(\mathrm{F}_{30 \mathrm{~ms}}\right)$ and at step $P\left(F_{M}\right)$ or, rather, the partial and total reductions of the plastoquinone $B$ pool $\left(Q_{B}{ }^{-}\right.$and $\left.Q_{B}{ }^{2-}\right)$, respectively, in addition to the accumulation of $Q_{A}^{-}$, exhibited greater 

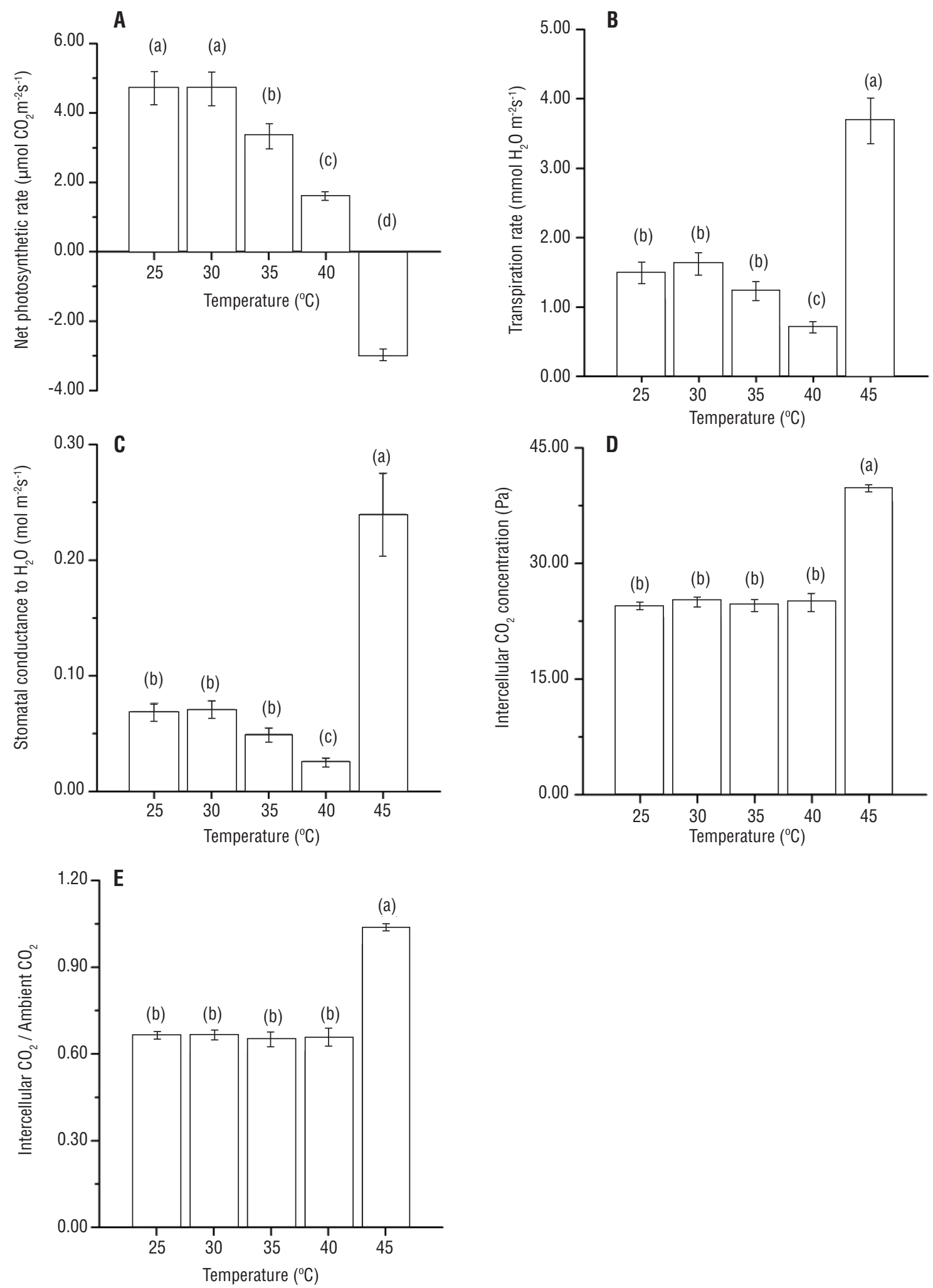

Figure 5. Variations in net photosynthetic rate, $\mathrm{A}, \mu \mathrm{mol} \mathrm{m} \mathrm{m}^{-2} \mathrm{~s}^{-1}(\mathrm{~A})$; transpiration rate, $\mathrm{E}, \mathrm{mmol} \mathrm{H}_{2} \mathrm{O} \mathrm{m}^{-2} \mathrm{~s}^{-1}(\mathrm{~B})$; stomatal conductance to $\mathrm{H}_{2} \mathrm{O}$, gs, mol m-2 $\mathrm{s}^{-1}(\mathrm{C})$; intercellular $\mathrm{CO}_{2}$ concentration, $\mathrm{Ci},(\mathrm{Pa})(\mathrm{D})$ and intercellular $\mathrm{CO}_{2} /$ ambient $\mathrm{CO}_{2}(\mathrm{E})$ of the leaf discs of peach subjected to different temperature. Bars indicate standard error $(n=10)$. The different letters indicate significant difference at $p<0.05$ (Tukey's test). 
values when the leaf discs were exposed to 25,30 and $35^{\circ} \mathrm{C}$, indicating a rapid increase in the polyphasic $\mathrm{Chl}$ a fluorescence which reflects an accumulation of the reduced states (Mathur et al., 2011). In addition, studies of the I-P phase of the fluorescence kinetics reflect the size of the pool of final acceptors on the PSI acceptor side (Strasser et al., 2004). However, the lowest fluorescence intensity at step $\mathrm{P}\left(\right.$ or $\mathrm{F}_{\mathrm{m}}$ ) observed under thermal stress, represented in this study by the temperatures of 40 and $45^{\circ} \mathrm{C}$, may be due to an increase in $\mathrm{k}_{\mathrm{N}}$ and, therefore, in an increase of the dissipated energy flux.

Under thermal stress, the decrease in $\varphi_{P_{0}}=F_{V} / F_{M}=$ $\mathrm{k}_{\mathrm{P}} /\left(\mathrm{k}_{\mathrm{P}}+\mathrm{k}_{\mathrm{N}}\right)=1 /\left(1+\left(\mathrm{k}_{\mathrm{N}} / \mathrm{k}_{\mathrm{P}}\right)\right)=1 /\left(1+1 /\left(\mathrm{k}_{\mathrm{P}} / \mathrm{k}_{\mathrm{N}}\right)\right)$ where $\mathrm{k}_{\mathrm{P}} / \mathrm{k}_{\mathrm{N}}$ $=F_{\mathrm{v}} / \mathrm{F}_{0}$ is decreasing (Table 1), reflecting damage to PSII (Chen and Cheng, 2009). These results are similar to those observed in rice leaves (Yamane et al., 1997) and in the leaves and peels of apples (Chen and Cheng, 2009). The drop in $\varphi_{E 0}$ may indicate the slowdown of $Q_{A}$ reduction, and the $\varphi_{\mathrm{E} 0}$ decrease corresponds to an increase in the relative variable fluorescence at step $\mathrm{J}\left(2_{\mathrm{ms}}\right)$ (Figure 1$)$. This is likely caused by the accumulation of reduced $Q_{A}$ (Bussotti et al., 2011).

The lowest values of $\varphi_{\mathrm{R} 0}$ may occur due to an increase in the efficiency of electron transport from $\mathrm{PQH}_{2}$ to the final electron receptors of PSI, $\delta_{R o}$ However, because the high temperature affects the PSI side donors, the efficiency with which an electron moves from the electron acceptors of the intersystem to the final acceptors of PSI was negatively affected, which contributed to this result.

The lower values of $\mathrm{PI}_{\mathrm{ABS}}$ may have been caused by the absorption of energy by inactive reaction centres, which results in lower RC/ABS values, in addition to a lower photochemical yield and a reduction in the yield of electron transport from $Q_{A}$ - to the intersystem electron acceptors (Table).

The greater amplitude of the L-band, revealed by the difference between the relative variable fluorescence values between the steps 0 and $\mathrm{K}$, is an indicator of the lower connectivity or less grouping of the PSII units (Yusuf et al., 2010). Furthermore, the connectivity between PSII units increases the use of excitation energy and is a significant factor for the stability of the photosynthetic system (Strasser et al., 2004), which suggests that the photosynthetic system can remain stable even after exposure to a temperature of $30^{\circ} \mathrm{C}$. Therefore, the appearance of the L-band is an effect that reflects a deviation from the stability of the system, which agrees with the concept of stress proposed by Strasser (1988), who describes stress as any established condition in which the forces of the system are outside of their ideal thermodynamic optimal states.

The intensity of the $\mathrm{Chl}$ a fluorescence transients is affected not only by the activity of the PSII side electron acceptors but also by the functional state of the donor side of the same photosystem (oxygen-evolving complex, OEC) (Strasser et al., 2004). In this context, the appearance of the K-band, hidden between steps 0 and $\mathrm{J}$, occurs due to the equilibrium established for electron transport. The K step, located at approximately $300 \mu \mathrm{s}$, is related to the deactivation of the OEC (Strasser et al., 2004); in leaf discs exposed to $45^{\circ} \mathrm{C}$, this step displays high values. A positive $K$ step corresponds to non-water electron donation to PSII (Strasser, 1975). A K step with large amplitude corresponds to an imbalance between the electron donor and electron acceptor sides of PSII, which reflects the dissociation of the $\mathrm{OEC}$, along with a progressive decrease in the rates of photochemical processes (Gururani et al., 2012).

At high temperatures, the electron donor capacity of the reaction centres of PSII is gradually reduced; consequently, the electron transport chain remains oxidised (Mathur et al., 2011; Oukarroum et al., 2012). This change alters the OJIP fluorescence transient curve, which appears to be a specific response to the high temperatures that is reflected in the total suppression of steps $\mathrm{J}$ and $\mathrm{I}$, in addition to the large variation in the $P$ step. This finding was also observed for wheat leaves (Mathur et al., 2011) and the leaves of Parmelina tiliacea (Oukarroum et al., 2012) when exposed to temperatures of 40 and $45^{\circ} \mathrm{C}$.

The gas exchanges of the peach leaf discs exposed to different temperatures for 30 minutes were drastically affected by the higher temperatures. For the net assimilation rate, that was measured immediately after the high temperature period, there was a significant decrease in apparent $\mathrm{CO}_{2}$ fixation, reduction beginning at $35^{\circ} \mathrm{C}$. In general, stress due to high temperatures causes a direct thermodynamic effect that suppresses biological processes, including the activities of the Rubisco enzyme and PSII.

The fact that the assimilation of $\mathrm{CO}_{2}$ is dependent on temperature may be attributed to the low activation level of the Rubisco enzyme (Wahid et al., 2007), which in turn is likely a consequence of the increased permeability of the thylakoid membranes and the reorganisation of the electron transport chain (Ducruet et al., 2007). Nevertheless, with an increase in temperature, the Rubisco enzyme increases its catalytic activity, and it is the low affinity of the enzyme 
for $\mathrm{CO}_{2}$ and its oxygenase activity that limit the potential increases in the photosynthetic rate (Wahid et al., 2007).

The stomatal conductance displayed patterns similar to those of photosynthesis at temperatures of $25,30,35$ and $40^{\circ} \mathrm{C}$, suggesting that the decrease in the photosynthetic rate is also related to stomatal closing at the higher temperatures. However, for the leaves exposed to $45^{\circ} \mathrm{C}$, the stomatal conductance reached a value 3.5 times greater than the values observed for the control. Stomatal opening has also been observed for bean and clover leaves exposed to temperatures of 40 and $45^{\circ} \mathrm{C}$ (Reynolds-Henne et al., 2010). The increase in stomatal conductance at high temperatures may be caused by changes in metabolism and membrane properties (Reynolds-Henne et al., 2010), which could explain the differences in the responses observed at different temperatures.

The photosynthetic electron transport chain was affected when peach leaf discs were exposed to temperatures of 40 and $45^{\circ} \mathrm{C}$. An increase in $F_{0}$ was observed at the elevated temperatures, and the $\mathrm{K}$ and $\mathrm{L}$ bands displayed large amplitudes. The parameters for gas exchanges were gradually and negatively affected by the increase in temperature, with the lowest rates of net assimilation observed at $45^{\circ} \mathrm{C}$.

\section{ACKNOWLEDGMENTS}

The CNPq, CAPES, FAPERGS, FINEP and Ministério da Ciência e Tecnologia, for the financial support.

\section{REFERENCES}

Bussotti F, Desotgiu R, Cascio C, Pollastrini M, Gravano E, Gerosa G, Marzuoli R, Nali C, Lorenzini G, Salvatori E, Manes F, Schaube M, Strasser RJ (2011) Ozone stress in woody plants assessed with chlorophyll a fluorescence. A critical reassessment of existing data. Environ. Exp. Bot. 73:19-30.

Chen LS, Cheng $L$ (2009) Photosystem 2 is more tolerant to high temperature in apple (Malus domestica Borkh.) leaves than in fruit peel. Photosynthetica 47:112-120.

Chen LS, Pengmin L, Cheng L (2008) Effects of high temperature coupled with high light on the balance between photooxidation and photoprotection in the sun-exposed peel of apple. Planta 228:745-756.

Ducruet JM, Peeva V, Havaux M (2007) Chlorophyll thermofluorescence and thermoluminescence as complementary tools for the study of temperature stress in plants. Photosynth. Res. 93:159-171.

Gururani MA, Upadhyaya CP, Strasser RJ, Woong JP, Park SW (2012) Physiological and biochemical responses of transgenic potato plants with altered expression of PSII manganese stabilizing protein. Plant Physiol. Biochem. 58:182-194.
Lawlor DW, Tezara T (2009) Causes of decreased photosynthetic rate and metabolic capacity in water-deficient leaf cells: a critical evaluation of mechanisms and integration of processes. Ann. Bot. 103:561-579.

Mathur S, Jajoo A, Mehta P, Bharti S (2011) Analysis of elevated temperature-induced inhibition of photosystem II using chlorophyll a fluorescence induction kinetics in wheat leaves (Triticum aestivum). Plant Biol. 13:1-6.

Oukarroum A, Strasser RJ, Schansker G (2012) Heat stress and the photosynthetic electron transport chain of the lichen Parmelina tiliacea (Hoffm.) Ach in the dry and the wet state: differences and similarities with the heat stress response of higher plants. Photosynth. Res. 111:303-14.

Petkova V, Denev ID, Cholakov D, Porjazov I (2007) Field screening for heat tolerant common bean cultivars (Phaseolus vulgaris L.) by measuring of chlorophyll fluorescence induction parameters. Sci. Hortic. 111:101-106.

Pushpalatha P, Sharma-Natu P, Ghildiyal MC (2008) Photosynthetic response of wheat cultivar to long-term exposure to elevated temperature. Photosynthetica 46:552-556.

Reynolds-Henne CE, Langenegger A, Mani J, Schenk N, Zumsteg A, Feller U (2010) Interactions between temperature, drought and stomatal opening in legumes. Environ. Exp. Bot. 68:37-43.

Strasser RJ, Govindjee (1992) The Fo and the 0-J-I-P fluorescence rise in higher plants and algae. In: Argyroudi-Akoyunoglou JH (ed.) Regulation of Chloroplast Biogenesis, pp. 423-426. Plenum Press, New York.

Strasser BJ, Strasser RJ (1995) Measuring fast fluorescence transients to address environmental questions: the JIP-test. In: Mathis P (ed), Photosynthesis: From Light to Biosphere, pp. 977-980. Kluwer Academic Publishers, The Netherlands.

Strasser RJ (1975) Studies on the oxygen evolving system in flashed leaves. In: Avron M (ed), Proceedings of the 3rd International Congress on Photosynthesis, pp. 497-503. Rehovot-Israel, Elsevier, Amsterdam.

Strasser RJ (1988) A concept for stress and its application in remote sensing. In: Lichtenthaler HK (ed), Applications of Chlorophyll Fluorescence, pp. 333-337. Kluwer Academic Publishers, The Netherlands.

Strasser RJ, Srivastava A, Govindjee (1995) Polyphasic chlorophyll a fluorescence transient in plants and cyanobacteria. Photochem. Photobiol. 61:32-42.

Strasser RJ, Srivastava A, Tsimilli-Michael M (2000) The fluorescence transient as a tool to characterize and screen photosynthetic samples. In: Yunus M, Pathre U, Mohanty P (ed). Probing Photosynthesis: Mechanisms, Regulation and Adaptation, pp. 445-483. Taylor \& Francis, London.

Strasser RJ, Tsimilli-Michael M, Srivastava A (2004) Analysis of the chlorophyll a fluorescence transient. In: Papageorgiou GC, Govindjee (ed). Chlorophyll a fluorescence: a signature of photosynthesis. Advances in Photosynthesis and Respiration Series, pp. 321-362. Kluwer Academic Publishers, Rotterda.

Strauss AJ, Kruger GHJ, Strasser RJ, Van Heerden PDR (2006) Ranking of dark chilling tolerance in soybean genotypes probed by the chlorophyll a fluorescence transient 0-J-I-P. Environ. Exp. Bot. 56:147-157.

Tóth SZ, Schansker G, Garab G, Strasser RJ (2007) Photosynthetic electron transport activity in heat-treated barley leaves: the role of internal alternative electron donors to photosystem II. Biochim. Biophys. Acta Bioenerg. 1767:295-305.

Tsimilli-Michael M, Strasser RJ (2008) In vivo assessment of plants' vitality: 
applications in detecting and evaluating the impact of Mycorrhization on host plants. In: Varma A (ed), Mycorrhiza, pp. 679-703. Springer, Berlin Heidelberg.

Wahid A, Gelani S, Ashraf M, Foolad MR (2007) Heat tolerance in plants: An overview. Environ. Exp. Bot. 6:199-223.

Yamane Y, Kashino Y, Koike H, Satoh K (1997) Increases in the fluorescence Fo level and reversible inhibition of Photosystem II reaction center by hightemperature treatments in higher plants. Photosynth. Res. 52:57-64.

Yamane Y, Kashino Y, Koike H, Satoh K (1998) Effects of high temperatures on the photosynthetic systems in spinach: Oxygen-evolving activi- ties, fluorescence characteristics and the denaturation process. Photosynth. Res. 57:51-59.

Yamane Y, Shikanai T, Kashino Y, Koike H, Satoh K (2000) Reduction of $Q A$ in the dark: Another cause of fluorescence Fo increases by high temperatures in higher plants. Photosynth. Res. 63:23-34.

Yusuf MA, Kumar D, Rajwanshi R, Strasser RJ, Tsimilli-Michael M, Govindjee, Sarin NB (2010) Overexpression of gamma-tocopherol methyl transferase gene in transgenic Brassica juncea plants alleviates abiotic stress: physiological and chlorophyll fluorescence measurements. Biochim. Biophys. Acta Bioenerg. 1797:1428-1438. 